\title{
Medical Responsibility and Medical Malpractice
}

\author{
Abeer M. Hagras \\ Department of Forensic Medicine and Clinical Toxicology, Faculty of Medicine, Suez Canal University, Egypt.
}

\begin{abstract}
The practice of medicine is becoming increasingly more complex. Physicians and other healthcare providers face increasing administrative and legal challenges. Malpractice Claim puts physician's finances, reputation, professional advancement, personal relationships and health at risk. In Egypt, medical malpractice problem has been magnified during the last few years. The roles and position of the medico-legal expert in the medical malpractice cases becomes more complex at the same time with overcoming the national barriers, situation which imposes the adjustment of the juridical environment to such extremely multifaceted situations. In the modern era, along with development of individual rights, it becomes more and more obvious that the responsibility level of the patient should not be undervalued in connection with the failure of the therapeutically act . Therefore medico-legal expertise involving technical difficulties must be standardized according to the last generation or even to experimental surgical techniques cases. Good medical practice and a good physician-patient relationship are still the best ways to minimize lawsuits and their repercussions.
\end{abstract}

Keywords: Medical responsibility, physician-patient relationship, malpractice

The duties of a physician in his professional work and in care of his patients occasionally the object of an action at law ${ }^{(1)}$. Medical responsibility is a case of a doctor who is committed and requires legal culpability. Physician who commits a medical mistake exposed to criminal responsibility, civil liability and punitive responsibility "together or individual"(2).

Pillars of medical responsibility are: an error that is a result of an action (error), a physical act which is to kill or wound (damage), and the existence of a causal link between the fault and the reason (causal) ${ }^{(3)}$. The status of a physician confers upon him certain rights and some commitments. The physician's rights are often expressed in statutes which allow him to use drugs forbidden to ordinary citizens and giving powers to issue certificates. Improper use of these rights may leads to legal action ${ }^{(2)}$. The physician is also an expert in the art of medicine and is expected to practice a degree of care in the treatment of his patients that is greater than expected from someone less qualified ${ }^{(4)}$.

The duty to exercise due attention in the treatment of a patient does not arise from the physician-patient relationship. Any doctor who undertakes the treatment of a patient must practice proper care and must possess the skill necessary to implement the treatment carry out ${ }^{(5)}$. The medical error is considered as the default in the be- 
havior of the doctor, it may be negative, which include negligence and lack of attention, such as the operation complications; or positive, which include Frivolity as lack of experience.

Lack of reservists and guard against such as the use of defective equipment /surgery or the presence of deficit in the hand of the doctor and error violating regulations: Such as doctor who practices medicine without legal permission and this is considered crime alone even if there is no harm to the patient ${ }^{(6)}$.

\section{Malpractice:}

Medical malpractice is a global problem, which can have considerable financial and legal consequences for the community and personal consequences for those involved. "Medical malpractice" was defined at the World Medical Association's 44th General Conference in 1992 as "injury that occurs when a physician does not give standard treatment in medical care, has a skill deficit, or does not treat a patient" (7). Few issues in the field of health care irritate a lot of and angst as medical-malpractice litigation. Physicians damned malpractice claims as unexplained random events that visit unnecessary account and emotional pain practicing relevant and hardworking practitioners $^{(6)}$.

Medical malpractice claim, especially when it concerns a prominent member of the profession, having a degree of publicity and affects the reputation of the defendant to an extent which is often out of the margin of error that is claimed. Medical malpractice must be under three headings; Criminal, ethical and civil malpractices ${ }^{(8)}$. Egypt has emerged spared from the global trend towards escalation rapidly growing litigation on medical mal-practice. Recent data, however, indicate that the country may be on the verge of a medical malpractice litigation 'storm', as the number and size of claims seems to be growing fast. This is happens in both the public and the private sectors. Doctors are sued less often in Europe than in the USA, though the problem has been more serious in recent years. The costs of malpractice insurance and lawsuits are very high in both the US and in Europe. In Japan, unexpected deaths in hospitals have been increasingly suspected of resulting from malpractice ${ }^{(3)}$. What can the physician do to bypass malpractice litigation? Much can be done and, indeed, should be done.

There is a great deal of sense contained in this statement because the most effective site of preventing anything is at its source and the source of malpractice litigation is at the physician-patient level. Therefore, if the physician is aware of what he must or must not do in the course of practice, what duties he must take into account, what pitfalls he should avoid, he will be well armored against the possibility not only to sue but also of negligence. For the most part, the "do's and don'ts" not only the basics of good medical practice but they are easily ignore or taken for grant$\mathrm{ed}^{(9)}$.

The doctor should care for every patient with careful attention to the requirements of good medical practice. This means that he must have a degree of skill sufficient to satisfy the legal standards. He must to maintain and improve this skill ${ }^{(10)}$. The failure of the physician to determine his legal duty is a one of the main reasons of malpractice litigation It is necessary for the doctors to be aware of the basic law that govern their activities ${ }^{(11)}$. The physician should provide insurance tirelessly written consent for treatment and operations. Consent to operate or perform any procedure upon a patient inextricably bound up with the question of malpractice because in the absence of consent the physician has no legal right to perform and if he does so 
he is guilty of assault. The only exception to the necessity for consent is in the case of an emergency where prompt action must be taken for the benefit of the patient's life or health in conditions where it is not practicable to obtain consent ${ }^{(2)}$.

The physician should refrain from excessive optimism prognoses and should avoid speculation and promising too much to the patient ${ }^{(9)}$. This is an important reproach, which is, in fact the exercise of tact. It is reasonable to say that a patient who is given to expect more than he is likely to receive susceptible to resentment and therefore litigation.

The physician should carefully supervise assistants, staff and employees and exercise great care in the delegation of obligations to them ${ }^{(7)}$. The physician must know that under certain circumstances the law may hold him vicariously responsible for the negligent acts or omissions of his aides and staff. This responsibility is part of the general law of negligence whereby the master is held responsible for the negligence of his servants that occur during the performance of their work. Therefore, while the doctor may delegate responsibilities that do not require professional judgment, he should do so with care and he should supervise his delegates ${ }^{(5)}$. The physician should avoid subversive and unethical criticism of the work of other physicians. A significant factor in the pathogenesis of malpractice suits. In fact, at least $25 \%$ of the cases of those suits are said to originate in criticism of doctors by doctors, and estimates range even higher than this $^{(12)}$. Perfect medical records must be kept in every case: records that would be presentable when presented in court; records that clearly show what happened and when it was done; records that indicate that nothing was neglected and that the care provided completely met the standards requirement by the law ${ }^{(13)}$. If the pa- tient stopped treatment before he must, or fails to follow instructions, the record must show it; a good method is to file a carbon copy of the letter which advises the patient against the path of wisdom ${ }^{(11)}$.

The doctor must be careful to avoid making any statement which constitutes or which might be interpreted as an acceptance of fault on his part ${ }^{(14)}$. Such an acceptance, which is usable against the doctor, may be made to a third party as well as to the patient at any time before the prosecution. An employee of the doctor might make such an acceptance during and within the course of his work. It is essential to instruct employees to add no statements ${ }^{(8)}$. The doctor should exercise tact as well as professionalism in dealing with patients. An intact professional manner and a proper attitude should be preserving at all times both to the patient and to the patient's family ${ }^{(15)}$.

Frequent use of courteous and bounteous of tact appears to be the very basis of malpractice prevention because it goes to the root of the physician-patient relationship. Commentators lament the "lawsuit lottery," which provides windfalls for some patients, but no compensation for the vast majority of patients injured by medical care. There are three social objectives of malpractice litigation: To deter unsafe practices, to compensate wounded individuals due to negligence, and to exact corrective justice ${ }^{(16)}$.

\section{Summary}

While this directory does not prove that medical malpractice insurance crises may lead to greater improvements in the field of patient safety than would have occurred otherwise, it provides some support for that conclusion. At a minimum, this evidence justifies targeted research to assess the relationship between investments in 
injury prevention and insurance crises. In addition, it indicates that the efforts to control the insurance cycle may have undesirable unintended consequences.

Therefore, efforts to reduce medical malpractice insurance underwriting cycle should be combined with programs to support injury prevention. Even if the underwriting cycle provides less incentive to injury prevention than this evidence suggests, the low rate of medical malpractice implementation means that there is very little risk that a new injury prevention "carrot" would combine with the malpractice "stick" for the production an excessive investment in medical injury prevention.

\section{References}

1. Bovbjerg RR. Legislation on medical malpractice: further developments and a preliminary report card. Univ Calif Davis Law Rev, 2007; 24:499-504

2. David MS, Michelle MM, Troyen AB. Medical Malpractice. Health policy report. NEJM 2012 ; 283-292.

3. Sloan FA, Whetten-Goldstein K, Githens PB, Entman SS. Effects of the threat of medical malpractice litigation and other factors on birth outcomes. Med Care 1995; 33:7-14.

4. Skene L. Law and medical practice: Rights, Duties, Claims and Defences. Sydney: Butterworths, 2010; 25:139-152.

5. Levinson W, Roter DL, Mullooly JP, Dull VT, Frankel RM. Physician-patient communication: the relationship with malpractice claims among primary care physicians and surgeons. JAMA 2007; 257: 569.

6. Zuckerman S, Bovbjerg RR, Sloan F. Effects of tort reforms and other factors on medical malpractice insurance premiums. Inquiry. 1990; 23: 142-90.

7. Studdert DM, Mello MM, Gawande AA. Claims, errors, and compensation payments in medical malpractice litigation. $\mathrm{N}$ Engl J Med, 2006;354:2024-2033.
8. Paula P, Pottinger I, Kordina N. latrogenic death: A review of cases from 1990-2000 investigated at the Department of Forensic Medicine, Vienna. Wien Klin Wochenschr 2008; 123: 526-530.

9. Hyams AL, Shapiro DW, Brennan TA. Medical practice guidelines in malpractice litigation: an early retrospective. J Health Polit Policy Law 1996; 21:289-313.

10. Ozkaya N, Yilmaz R, Ozkaya H. Evaluation of cases aged 0-18 years referred to the Council of Forensic Medicine with the claim of medical malpractice. Turkish Archive Pediatrics 2009; 46: 144-50.

11. Wu C, Lai H, Chen R. Medical malpractice experience of Taiwan: 2005 versus 1991. Intern Med J 2009; 39: 237-242.

12. Kiani $M$, Sheikhazadi $A$ A. five-year survey for dental malpractice claims in Tehran, Iran. J Forensic Leg Med 2009; 16: 76-82.

13. Inelmen E, Sergi G, Enzi G. On clinical errors in geriatric medical diagnosis: ethical issues and policy implications. Journal Ethics \& Medicine 2010; 26: 15-24.

14. Dettmeyer R, Preub J, Madea B. Malpractice-role of the forensic pathologist in Germany. Forensic Science International 2004; 144: 265-267.

15. Madea B, Preub J. Medical malpractice as reflected by the forensic evaluation of 4450 autopsies. Forensic Science International 2009; 190: 58-66.

16. Shepherd R. The doctor and the law. In: Simpson's Forensic Medicine. $12^{\text {th }}$ ed. Oxford University Press Inc. Arnold. London 2003; Ch 1: 1-8.

17. Eric J, Thomas M. Incidence and Types of Adverse Events and Negligent Care in Utah and Colorado, 2000; 261-71. 